\title{
Analisis Simpang Bersinyal \\ Di Simpang Tanjung Alam Kabupaten Agam
}

\author{
Masril \\ Email : mril6030@gmail.com \\ Dosen Tetap FT. UMSB
}

\begin{abstract}
Abstrak: Kemacetan dan masalah lalu lintas sering terjadi pada beberapa persimpangan di jalan raya. Oleh karena itu perlu penanganan yang efisien dan optimal, perencanaan TrafficLights atau Alat Pemberi Isyarat Lalu lintas (APILL) adalah satu alternatif yang perlu untuk mengatasi permasalahan lalu lintas di perkotaan. Didalam penelitian skripsi ini yang meneliti tentang perencanaan simpang bersinyal. Lokasi penelitian di Simpang Tanjung Alam, Kabupaten Agam yang menghubungkan JL. Lintas Tengah Sumatera, JL. Raya Ampang Gadang dan JL. Raya Mansoer Thaib. Di persimpangan ini kondisi arus lalu lintas cukup ramai dan padat (jam sibuk : 07.00-08.00 WIB), sering terjadi kemacetan dan pengendara yang melanggar rambu lalu lintas. Tinjauan dan analisa dilakukan berdasarkan data yang diperoleh dari lokasi penelitian.Didalam perhitungan didapatkan hasil : Kapasitas (C) 3921 smp/jam, Derajat Kejenuhan (DS) 1,7 dan Tundaan (D) $\mathrm{D}_{\text {tot }}=14,39 \mathrm{dtk} / \mathrm{smp}$. Dari perhitungan tersebut akan diperoleh juga Waktu Siklus (Co) untuk 4 fase $=80$ detik dengan waktu hijau aktual (Selatan $=14$ detik, Barat $=12$ detik, Utara $=13$ detik dan Selatan $=21$ detik). Dari hasil penelitian menyimpulkan bahwa dengan adanya Traffic Lights atau APILL permasalahan lalu lintas yang terjadi di Simpang Tanjung Alam, Kabupaten Agam akan berkurang.
\end{abstract}

Kata kunci : Traffic Lights, waktu tundaan, derajat kejenuhan

Abstract: Congestion and traffic problems often occur at intersections on the highway. Therefore it is necessary that an efficient and optimal handling, planning Traffic Lights or Paraphernalia Gesture Traffic (APILL) is an alternative that needs to solve traffic problems in urban areas. Inside this thesis research that examines the intersection of planning. The research location in Simpang Tanjung Alam, Agam connecting JL. Central Lintas Sumatera, JL. Ampang Kingdom Tower and JL. Kingdom Mansoer Thaib. At this junction the traffic condition is quite crowded and congested (peak hours: 7:00 to 8:00 $\mathrm{pm}$ ), frequent traffic jams and motorists who violate traffic signs. Overview and analysis is based on data obtained from the study site. In the calculation of the results obtained:Dtot $=14.39 \mathrm{sec} / \mathrm{smp}$. From these calculations will be obtained also Cycle Time (Co) for 4 phase $=80$ seconds with a time of actual green $($ South $=14$ seconds, West $=12 \mathrm{sec}$, North $=13 \mathrm{sec}$ and East $=21 \mathrm{sec}) .$. From the results of the study concluded that the traffic Lights or APILL their traffic problems that occur in Simpang Tanjung Alam, Agam regency will be reduced.

Keywords: Traffic Lights, time delay, the degree of saturation

\section{PENDAHULUAN}

\section{A . Latar Belakang}

Pertemuan jalan atau yang sering disebut persimpangan jalan merupakan tempat bertemunya arus lalu lintas dari dua jalan atau lebih dan merupakan suatu titik tempat bertemunya berbagai pergerakan yang tidak sama arahnya baik pergerakan yang dilakukan orang dengan kendaraan maupun tanpa kendaraan(pejalankaki). Persimpangan jalan mempunyai peranan yang sangat penting guna menjamin kelancaran arus lalu lintas. Persimpangan harus dilengkapi dengan pengaturan lalu lintas karena merupakan hal yang paling kritis dalam pergerakan lalu lintas secara menyeluruh pada jaringan jalan. Kabupaten Agam mempunyai letak yang sangat strategis pada jalur utama transportasi di Provinsi Sumatera Barat.

Meningkatnya pertumbuhan jumlah penduduk, jumlah kendaraan pribadi serta sistem angkutan umum lainnya di Indonesia akan menciptakan permasalahan.

Akibatnya terjadi peningkatan pengguna jaringan lalu lintas, sehingga perlu ditunjang dengan pelayanan fasilitas-fasilitas lalu lintas 
yang memadai, terutama pada persimpangan jalan yang potensial menimbulkan hambatan bila tidak ditangani secara teknis. Simpang Tanjung Alam, Kabupaten Agam merupakan simpang tak bersinyal yang menghubungkan JL. Lintas Tengah Sumatera, JL. Raya Ampang Gadang dan JL. Raya Mansoer Thaib. Simpang-simpang tersebut terletak di kawasan bisnis dan pendidikan.

Hambatan samping berupa naik turunnya penumpang angkutan umum di sekitar simpang sehingga mengurangi kapasitas jalan dan menyebabkan penurunan kecepatan bagi pengendara yang melalui jalan tersebut. Kondisi diatas menyebabkan terjadinya kemacetan pada simpang Tanjung Alam, Kabupaten Agam yaitu terjadi antrian yang cukup panjang di lengan simpang. Dengan demikian perlu dilakukan "Perencanaan Simpang Bersinyal di Simpang Tanjung Alam, Kabupaten Agam".

Tujuan dari penelitian ini adalah untuk mengetahui mengetahui volume lalu lintas di simpang Tanjung Alam, Kabupaten Agam, untuk mengetahui hambatan samping di simpang Tanjung Alam, Kabupaten Agam. Dan untuk membuat perencanaan simpang bersinyal berdasarkan MKJI, tahun 1997

\section{B . Rumusan Masalah}

Di dalam penelitian yang berjudul "Analisis Simpang Bersinyal di Simpang Tanjung Alam, Kabupaten Agam”, maka penulis merumuskan permasalahan sebagai berikut :

a.Bagaimana kondisi eksisting simpang Tanjung Alam terhadap arus lalu lintas sekarang?

b. Perlukah perencanaan simpang bersinyal pada simpang Tanjung Alam, Kab. Agam?

\section{C.Maksud Dan Tujuan Penelitian}

Tujuan dan maksud dari penelitian ini adalah untuk mengetahui :

a.Untuk mengetahui volume lalu lintas di simpang Tanjung Alam, Kabupaten Agam

b. Untuk mengetahui hambatan samping di simpang Tanjung Alam, Kabupaten Agam.
c.Untuk membuat perencanaan simpang bersinyal berdasarkan MKJI, tahun 1997.

\section{Ruang Lingkup/Batasan Penelitian}

Pembatasan masalah dalam penelitian ini dibatasi oleh :

a. Survey volume lalu lintas yang dilakukan pada jam sibuk pagi pukul 07.00-09.00, jam sibuk siang pukul 12.00-14.00, dan jam sibuk sore pukul 16.00-18.00 pada hari kerja.Perencanaan simpang bersinyal berdasarkan MKJI, 1997 dengan memprediksi pertumbuhan lalu lintas 5 tahun mendatang

\section{KAJIAN PUSTAKA}

\subsection{Tinjauan Pustaka}

Pembinaan dan Penyelenggaraan lalu lintas dan angkutan jalan diatur dalam UU nomor 14 Tahun 1992 pasal 4. Adapun pokokpokok yang terkandung dalam ketentuan tersebut dapat diuraikan sebagai berikut

1. Memuat ketentuan bahwa negara mempunyai hak penguasaan atas penyelenggaraan lalu lintas dan angkutan jalan, wewenang pembinaan dan arah pembinaan.

2. Pengertian hak penguasaan oleh negara tersebut adalah bahwa negara mempunyai hak pengatur penyelenggaraan lalu lintas dan angkutan jalan, yang pelaksanaannya dilakukan oleh pemerintah berupa pembinaan.

3. Perwujudan pembinaan tersebut meliputi :

- Aspek pengaturan, mencakup perencanaan, perumusan dan penentuan kebijaksanaan umum maupun tekbis.

- Aspek pengendalian, berupa pengarahan dan bimbingan terhadap penyelenggaraan lalu lintas dan angkutan jalan.

- Aspek pengawasan adalah pengawasan terhadap penyelenggaraan lalu lintas dan angkutan jalan.

Beberapa ketentuan yang dimaksud adalah :

1. Rekayasa lalu lintas

Pengertian rekayasa lalu lintas meliputi perencanaan, pengadaan, pemasangan 
dan pemeliharaan fasilitas kelengkapan serta rambu-rambu lalu lintas, marka jalan, lampu lalu lintas dan fasilits keselamatan lalu lintas.

2. Manajemen lalu lintas

Manajemen lalu lintas adalah meliputi kegiatan perencanaan, pengaturan, pengawasan dan pengendalian lalu lintas yang bertujuan untuk keselamatan, keamanan, ketertiban dan kelancaran lalu lintas.

Untuk mewujudkan tujuan manajemen lalu lintas sebagaimana dimaksud diatas, diperlukan dukungan perangkat keras sehingga diperlukan rekayasa lalu lintas yang meliputi kegiatan antara lain :

1. Perencanaan yang meliputi kegiatan :

- Kebutuhan : memuat jumlah dan jenis perlengkapan pada setiap lokasi.

- Pengadaan : memuat alokasi pengadaan dan distribusi.

- Pemasangan : memuat jadwal pemasangan .

- Pemeliharaan : memuat kegiatan rutin pemeliharaan seluruh perlengkapan jalan.

- Penyusunan program perwujudannya merupakan program menyeluruh balik rencana kegiatan maupuin keuangan.

2. Pelaksanaan program meliputi kegiatan pengadaan, pemasangan, pemeliharaan dan penghapusan.

\subsection{Pengendalian Persimpangan.}

Kriteria bagi persimpangan yang sudah harus menggunakan APILL adalah :

1. Arus minimal lalu lintas yang menggunakan rata-rata diatas 750 kendaraan/jam selama 8 jam dalam sehari.

2. Bila waktu menunggu/tundaan ratarata kendaraan di persimpangan telah melampaui 30 detik.

3. Persimpangan digunakan oleh ratarata lebih dari 175 pejalan kaki/jam selama 8 jam dalam sehari.

4. Sering terjadi kecelakaan pada persimpangan yang bersangkutan.

5. Atau merupakan kombinasi dari sebabsebab yang disebutkan diatas.

Tujuan Pengaturan Simpang Bersinyal
Pada umumnya pengaturan lalu lintas dengan menggunkan sinyal digunakan untuk beberapa tujuan, antara lain adalah :

1. Menghindari terjadinya kemacetan pada simpang akibat konflik lalu lintas.

2. Memberi kesempatan kepada kendraan lain dan pejalan kaki dari jalan simpang yang lebih kecil untuk memotong jalan utama.

3. Mengurangi terjadinya kecelakaan lalu lintas akibat pertemuan kendaraan yang berlawanan arah.

Beberapa definisi umum yang perlu diketahui dalam kaitannya dengan permasalahan simpang bersinyal diantaranya adalah :

a. Tundaan (delay) adalah waktu tempuh tambahan yang diperlukan untuk melalui simpang (detik).

b. Panjang antrian adalah panjang antrian kendaran dalam suatu pendekatan (meter).

c. Antrian adalah jumlah kendaraan yang antri dalam suatu pendekat kendaraan (meter).

d. Fase adalah bagian dari siklus sinyal dengan lampu hijau disediakan bagi kombinasi tertentu dari gerakan lalu lintas.

e. Waktu siklus adalah waktu untuk urutan lengkap dari indikasi sinyal (detik).

f. Waktu hijau adalah waktu nyala lampu hijau dalam suatu pendekat (detik).

g. Rasio adalah perbandingan waktu hijau dengan waktu siklus dalam suatu pendekat.

h. Waktu merah semua adalah waktu sinyal merah menyala secara bersamaan pada semua pendekat yang yang dilayani oleh dua fase sinyal yang berurutan (detik).

i. Waktu antar hijau adalah jumlah anatar periode kuning dengan waktu merah semua antara dua fase sinyal berurutan (detik)

J.Waktu hilang adalah jumlah semua periode antar hijau dalam siklus yang 
lengkap atau beda antara waktu siklus dengan jumlah waktu hijau dalam semua fase yang berurutan (detik)

\subsection{Optimasi Simpang Bersinyal}

Faktor-faktor yang dapat dipakai untuk mempengaruhi kapasitas suatu simpang meliputi :

1. Jumlah lajur yang cukup disediakan untuk mencegah agar volume yang tinggi tidak akan mengurangi kecepatan samapai dibawah optimum pada kondisi rencana, dan aliran yang besar harus dipisahkan arahnya.

2. Kapasitas yang tinggi membutuhkan keseragaman kecepatan kendaraan dan perbedaan kecepatan relatif kecil pada tempat masuk dan keluar.

3. Gerakan belokan yang banyak membutuhkan keistimewaankeistimewaan seperti jalur tambhan yang terpisah.

4. Radius yang cukup tinggi untuk berbagai tipe kendaraan yang ada untuk menghindari pelanggaran batas terhadap jalur disampinggya dan tepi lapis perkerasan harus bebas dari rintangan.

5. Kelandaian yang sesuia untuk berbagai tipe dan jumlah kendaraan yang ada atau ketentuan khusus harus dibuat untuk tingkat-tingkat tertentu.

\section{METODE PENELITIAN}

\section{Lokasi Penelitian}

Lokasi penelitian bertempat di simpang Tanjung Alam pada JL. Raya Lintas Sumatera (jalan arteri), JL. Raya Mansoer Thaib dan JL. Ampang Gadang (jalan kolektor)

\section{Metode Pengumpulan Data}

\section{Observasi}

Observasi atau pengamatan merupakan salah satu teknik pengumpulan data/fakta yang cukup efektif untuk mempelajari suatu sistem. Observasi adalah melakukan pengamatan langsung suatu kegiatan yang sedang berlangsung. Dalam penelitian ini penulis melakukan observasi untuk menyajikan gambaran, dokumentasi atau kejadian nyata yang terjadi di persimpangan tersebut.

2. Dokumentasi
Dokumentasi adalah cara pengumpulan data dengan cara mempelajari arsip atau dokumendokumen yaitu setiap bahan tertulis, baik internal maupun eksternal yang berhubungan dengan masalah yang dibahas dalam penelitian. Penulis melakukan dokumentasi di lapangan guna mengetahui kondisi arus lalu lintas dan geometri pada persimpangan tersebut.

3. Data Sekunder

Internet merupakan salah satu media untuk mencari referensi untuk mengumpulkan teoriteori maupun cara-cara penulisan. Di sini penulis mengumpulkan teori maupun rumusrumus mengenai traffic lights atau APILL. Data-data sekunder ini diambil berdasarkan nilai-nilai yang sudah ada di MKJI, 1997.

\section{a. Data Primer}

Dalam pengambilan data primer ada 2 tahap yang sangat diperlukan dalam penelitian ini, yaitu :

\section{Pengambilan data di lokasi penelitian}

Pengambilan data di lokasi penelitian menggunakan alat sebagai berikut :

- Meteran 30 meter

- Kamera digital

- Alat tulis

- Formulir Survey

- GPS

Variabel yang akan diukur adalah

- Lebar jalan

- Jumlah dan lebar lajur

- Volume lalu lintas

- Hambatan samping

Pengambilan data geometrik dan kondisi jalan di persimpangan dilakukan dengan mengukur langsung ke lokasi penelitian.

\section{Ekstraksi data}

Untuk data volume lalu lintas yang melewati persimpangan, dilakukan observasi selama 1 hari kerja dan terbagi atas 3 bagian yaitu sibuk pagi pada jam 07.00-09.00, sibuk siang pada jam 12.00-14.00 dan pada jam 16.0017.00.Perhitungan kendaraan yang dihitung digolongkan menjadi 4 kategori yaitu :

- Kendaraan ringan (LV), meliputi : mobil penumpang (angkot), minibus, mobil pribadi dan pick up.

- Kendaraam berat (HV), meliputi : truk dan bus.

- Sepeda motor (MC).

- Kendaraan tak bermotor (UM), meliputi : sepeda, becak, delman dan lainya. 
Untuk data hambatan samping yaitu kendaraan yang parkir di bahu jalan, kendaraan yang keluar masuk, kendaraan yang menaik turunkan penumpang, pejalan kaki yang tidak tertib, dan banyaknya penyebrang jalan.

\section{b. Data Sekunder}

Pengumpulan data sekunder untuk menunjang penelitian. Data tersebut diperoleh dari sejumlah laporan dan dokumen yang telah disusun oleh instansi terkait serta hasil studi literatur lainnya. Data yang dibutuhkan yaitu : Peta Kabupaten Agam, Peta Jaringan Jalan, dan jumlah pertumbuhan kendaraan di Kabupaten Agam.

\section{Analisa Data Penelitian}

Prosedur perhitungan untuk menganalisis persimpangan dengan APILL adalah sebagai berikut :

1. Pengumpulan data, yang meliputi

- Kondisi geometrik, pengaturan lalu lintas dan lingkungan

- Survey volume lalu lintas dan hambatan samping.

2. Pengaturan fase, waktu

pengosongan dan waktu hilang, yang meliputi :

- Pengaturan fase

- Waktu pengosongan dan waktu hilang

3. Pengaturan waktu siklus dan waktu hijau, yang meliputi :

- Lebar efektif MP

- Arus jenuh dasar

- Faktor koreksi

- Nisbah arus/arus jenuh

- Waktu siklus dan waktu hijau

4.Kapasitas dan peningkatannya, yang meliputi:

- Kapasitas

- Peningkatan

5. Unjuk kerja, yang meliputi :

- Persiapan

- Panjang antrian

- Kendaraan berhenti

- Tundaan

\section{ANALISIS DATA}

\section{Sketsa Lokasi Penelitian}

Peneltian dilakukan di Simpang Tanjung Alam, Kabupaten Agam.

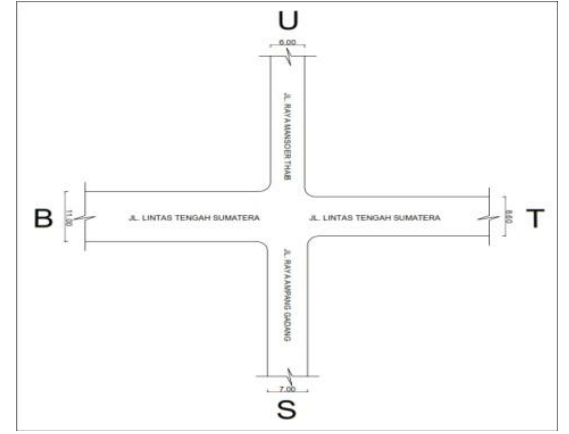

Metodologi

1. Menentukan kapasitas ( C )

2. Menentukan derajat kejenuhan ( DS )

3. Menentukan tundaan (D)

Menentukan peluang antrian

Tabel 4.1 : Kode Simpang Tak Bersinyal

\begin{tabular}{|c|c|c|c|}
\hline $\begin{array}{c}\text { Kode } \\
\text { Simpang }\end{array}$ & $\begin{array}{c}\text { Jumlah } \\
\text { Lengan } \\
\text { Simpang }\end{array}$ & $\begin{array}{c}\text { Jumlah } \\
\text { Lajur } \\
\text { Jalan } \\
\text { Simpang }\end{array}$ & $\begin{array}{c}\text { Jumlah } \\
\text { Lajur } \\
\text { Jalan } \\
\text { Simpang }\end{array}$ \\
\hline 322 & 3 & 2 & 2 \\
324 & 3 & 2 & 4 \\
342 & 3 & 4 & 2 \\
422 & 4 & 2 & 2 \\
424 & 4 & 2 & 4 \\
444 & 4 & 4 & 4 \\
\hline
\end{tabular}

Sumber : MKJI 1997

\section{a. Kapasitas}

Yaitu kapisatas total untuk seluruh lengan persimpangan, yaitu hasil perkalian antara kapsitas dasar (Co) untuk kondisi ideal dan faktorfaktor koreksi (F) dengan memperhitungkan pengaruh kondisi sesungguhnya terhadap kapasitas

Rumus yag digunakan

$C=C_{0} \times F_{w} \times F_{m} \times F_{c s} \times F_{r s u} \times F_{\text {lt }} \times F_{r t} \times F_{m i}$ (smp/jam)

Tabel 4.2 : Co $=$ Kapasitas Dasar

\begin{tabular}{|c|c|}
\hline Tipe Simpang & $\begin{array}{c}\text { Kapasitas dasar (co) } \\
\text { SMP/Jam }\end{array}$ \\
\hline 322 & 2700 \\
342 & 2900 \\
324 atau 344 & 3200 \\
422 & 2900 \\
\hline
\end{tabular}


424 atau 422

3400

\section{Sumber : MKJI 1997}

$F_{w}=$ Faktor penyelesaian lebar pendekat

$$
\mathrm{F}_{\mathrm{w}}=0,7+0,0086 \text {. We }
$$

- Lebar pendekatan rata-rata

$W e=\frac{\frac{a}{2}+b+\frac{c}{2}+\frac{d}{2}}{4}$

Keterangan:

$\mathrm{a}=11 \mathrm{~m} \quad\left(\mathrm{Jl}\right.$. Lintas Tengah $_{\mathrm{O}}$ Sumatera/Bukittinggi : Barat)

$\mathrm{b}=8.6 \mathrm{~m} \quad(\mathrm{Jl}$. Lintas Tengah Sumatera/Payakumbuh : Timur)

$\mathrm{c}=7 \mathrm{~m}$ ( Jl. Raya Ampang Gadang/Padang Luar : Selatan )

$\mathrm{d}=6 \mathrm{~m}$ ( Jl. Raya Mansoer Thaib/Kamang : Utara )

$$
\begin{aligned}
& W e=\frac{\frac{a}{2}+b+\frac{c}{2}+\frac{d}{2}}{4} \\
& W e=\frac{\frac{11}{2}+8.6+\frac{7}{2}+\frac{6}{2}}{4}
\end{aligned}
$$

$\mathrm{We}=5.15$

Jadi $: F_{\mathrm{w}}=0.7+0.0086 \times \mathrm{We}$

$$
\begin{aligned}
\mathrm{F}_{\mathrm{w}} & =0.7+0.0086 \times 5.15 \\
\mathrm{~F}_{\mathrm{w}} & =0.74
\end{aligned}
$$

$\circ \mathbf{F}_{\mathbf{m}}=$ Faktor penyesuaian median jalan utama

Tabel 4.3 : Faktor penyesuaian median jalan utama

\begin{tabular}{|c|c|c|}
\hline Uraian & $\begin{array}{c}\text { Type } \\
\text { Median }\end{array}$ & Fm \\
\hline $\begin{array}{c}\text { Tidak ada median pada } \\
\text { jalan utama }\end{array}$ & Tidak ada & 1.0 \\
Ada median $<4 \mathrm{~m}$ & Sempit & 1.0 \\
Ada median $>4 \mathrm{~m}$ & Lebar & 1.2 \\
\hline
\end{tabular}

Sumber : MKJI 1997

$\circ \quad \mathbf{F}_{\mathrm{cs}}=$ Faktor Penyesuai Ukuran Kota

Tabel 4.4 :faktor penyesuai ukuran kota

Sumber : MKJI 1997

\begin{tabular}{|c|c|c|}
\hline Uraian & Penduduk & Fcs \\
\hline $\begin{array}{c}\text { Sangat } \\
\text { Kecil }\end{array}$ & $<0.1$ & 0.82 \\
\hline Kecil & $0.1-0.5$ & 0.88 \\
\hline Sedang & $0.5-1.0$ & 0.94 \\
\hline Besar & $1.0-3.0$ & 1.00 \\
\hline $\begin{array}{c}\text { Sangat } \\
\text { Besar }\end{array}$ & $>3.0$ & 1.05 \\
\hline
\end{tabular}

$F_{\text {rsu }}=$ Faktor Penyesuaian Type Lingkungan Jalan, Hambatan Samping, Kendaraan Tak Bermotor

Tabel 4.5:faktor penyesuaian type lingkungan jalan, hambatan samping, kendaraan tak bermotor.

Sumber : MKJI 1997

$F_{\text {It }}=0.84+0.0161 \times$ Plt \%

$\mathrm{F}_{\mathrm{lt}}=0.84+0.0161 \times 29.8 \%$

$\mathrm{F}_{\mathrm{lt}}=1.32$

$\mathrm{F}_{\mathrm{rt}}=1.0$ ( Untuk simpang 4 lengan )

$\mathrm{F}_{\mathrm{MI}}=$ Faktor penyesuaian rasio arus jalan

\begin{tabular}{|c|c|c|}
\hline TS & $\mathbf{P}_{\mathrm{MI}}$ & $\mathbf{F}_{\mathrm{MI}}$ \\
\hline 422 & $\begin{array}{c}0,1- \\
0,9\end{array}$ & $\begin{array}{l}\mathbf{F}_{\mathrm{MI}} \\
1,19\end{array}$ \\
\hline \multirow[b]{2}{*}{$424 / 444$} & $\begin{array}{c}0,1- \\
0,3\end{array}$ & $\begin{aligned} & \mathbf{F}_{\mathrm{MI}}=16,6 \times \mathrm{P}_{\mathrm{MI}}{ }^{4}-33,3 \times \mathrm{P}_{\mathrm{MI}}^{3}+ \\
& 25,3 \times \mathrm{P}_{\mathrm{MI}}{ }^{2}-8,6 \times \mathrm{P}_{\mathrm{MI}}+1,95\end{aligned}$ \\
\hline & $\begin{array}{c}0,3- \\
0,9\end{array}$ & $\begin{array}{l}\mathbf{F}_{\mathrm{MI}}=1,11 \times \mathrm{P}_{\mathrm{MI}}^{2}-1,11 \times \mathrm{P}_{\mathrm{MI}}+ \\
1,11\end{array}$ \\
\hline \multirow{2}{*}{322} & $\begin{array}{c}0,1- \\
0,5\end{array}$ & $\begin{array}{l}\mathbf{F}_{\mathrm{MI}}=1,19 \times \mathrm{P}_{\mathrm{MI}}^{2}-1,19 \times \mathrm{P}_{\mathrm{MI}}+ \\
1,19\end{array}$ \\
\hline & $\begin{array}{c}0,5- \\
0,9\end{array}$ & $\begin{array}{l}\mathbf{F}_{\mathrm{MI}}=0,74-0,595 \times \mathrm{P}_{\mathrm{MI}}^{2}+0,595 \mathrm{x} \\
\mathrm{P}_{\mathrm{MI}}{ }^{2}\end{array}$ \\
\hline \multirow{2}{*}{342} & $\begin{array}{c}0,1- \\
0,5\end{array}$ & $\begin{array}{l}\mathbf{F}_{\mathrm{MI}}=1,19 \times \mathrm{P}_{\mathrm{MI}}^{2}-1,19 \times \mathrm{P}_{\mathrm{MI}}+ \\
1,19\end{array}$ \\
\hline & $\begin{array}{c}0,5- \\
0,9\end{array}$ & $\mathbf{F}_{\mathrm{MI}}=2,38 \times \mathrm{P}_{\mathrm{MI}}{ }^{2}-2,38 \times \mathrm{P}_{\mathrm{MI}}+1,49$ \\
\hline $324 / 344$ & $0,1-$ & $\mathbf{F}_{\mathrm{MI}}=16,6 \times \mathrm{P}_{\mathrm{MI}}{ }^{4}-33,3 \times \mathrm{P}_{\mathrm{MI}}^{3}+$ \\
\hline
\end{tabular}
simpang (minor)

\begin{tabular}{|c|c|c|c|c|c|c|c|}
\hline \multirow{2}{*}{$\begin{array}{c}\text { Kelas Tipe } \\
\text { Lingkungan }\end{array}$} & Kelas Hambatan & \multicolumn{4}{|c|}{ Rasio Kendaraan tidak bermotor } \\
\hline Jalan RE & Samping SF & \multicolumn{4}{|c|}{ UM/MV (pum) } \\
\cline { 2 - 8 } & & $\mathbf{0 . 0 0}$ & $\mathbf{0 . 0 5}$ & $\mathbf{0 . 1 0}$ & $\mathbf{0 . 1 5}$ & $\mathbf{0 . 2 0}$ & $0 \mathbf{0 . 2 5}$ \\
\hline \multirow{3}{*}{ Komersial } & Tinggi & 0.93 & 0.88 & 0.84 & 0.79 & 0.74 & 0.70 \\
\cline { 2 - 8 } & Sedang & 0.94 & 0.89 & 0.85 & 0.80 & 0.75 & 0.70 \\
\cline { 2 - 7 } & Rendah & 0.95 & 0.90 & 0.86 & 0.81 & 0.76 & 0.71 \\
\hline \multirow{3}{*}{ Pemukiman } & Tinggi & 0.96 & 0.91 & 0.86 & 0.82 & 0.77 & 0.72 \\
\cline { 2 - 7 } & Sedang & 0.97 & 0.92 & 0.87 & 0.82 & 0.77 & 0.73 \\
\cline { 2 - 7 } & Rendah & 0.98 & 0.93 & 0.88 & 0.83 & 0.78 & 0.74 \\
\hline Akses & Tinggi/Sedang/Rendah & 1.00 & 0.95 & 0.90 & 0.85 & 0.80 & 0.75 \\
\hline
\end{tabular}

Tabel 4.6 : Faktor penyesuaian rasio arus jalan simpang (minor) 


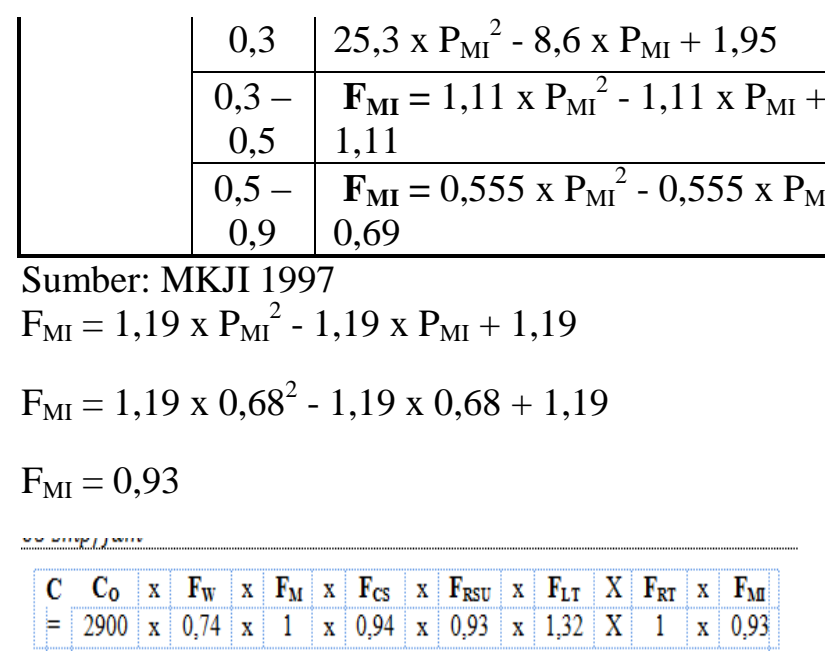

\section{Tundaan (D)}

a. Tundaaan rata-rata seluruh simpang (dtk/smp)

$$
\begin{aligned}
\mathrm{DS} & \leq 0,6 \rightarrow \quad \mathrm{D}_{\text {tot }}=2+8,2078 \times \mathrm{DS} \\
& \mathrm{DS}>0,6 \underset{1,0504}{\rightarrow} \\
\mathrm{D}_{\text {to }} & =\frac{1,2742-0,2042 \times D S)}{(0,2720} \\
\mathrm{DS} & =1,70>0,6 \\
\mathrm{D}_{\text {tot }} & =\frac{1,0504}{(0,2742-0,2042 \times D S)} \\
\mathrm{D}_{\text {tot }} & =\frac{1,0504}{(0,073)} \\
\mathrm{D}_{\text {tot }} & =14,39 \mathrm{dtk} / \mathrm{smp}
\end{aligned}
$$

Tundaan rata-rata jalan utama (dtk/smp)

$$
\begin{aligned}
& \mathrm{D}_{\mathrm{MA}}=\frac{1}{(0,346-0,246 x D S)} \\
& \mathrm{D}_{\mathrm{MA}}=\frac{1}{(0,346-0,246 \mathrm{G1} 1,70)} \\
& \mathrm{D}_{\mathrm{MA}}=\frac{1}{(0,072)} \\
& \mathrm{D}_{\mathrm{MA}}=13,89 \text { (dtk/smp) }
\end{aligned}
$$

\section{Tundaan rata-rata jalan simpang ( $\mathrm{dtk} / \mathrm{smp})$}

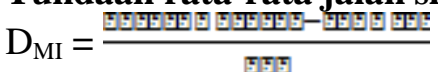

Keterangan:

Qtotal $=$ Arus total $\quad \rightarrow(\mathrm{smp} / \mathrm{jam})$

Dtotal $=$ Tundaan rata-rata total $\rightarrow(\mathrm{dtk} / \mathrm{jam})$

$\mathrm{Q}_{\mathrm{MA}}=$ Arus total jalan utama

$$
\rightarrow \text { (smp/jam) }
$$

$\mathrm{D}_{\mathrm{MA}}=$ Tundaan rata-rata jalan utama $\rightarrow$ (dtk/jam)

$\mathrm{Q}_{\mathrm{MI}}=$ Arus total jalan simpang (minor)

$$
\rightarrow \text { (smp/jam) }
$$

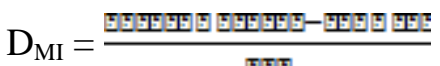

$\mathrm{D}_{\mathrm{MI}}=\frac{3921 \text { ⿴囗1 } 14,39-2681 \text { 团 13,89 }}{1240}$
$\mathrm{D}_{\mathrm{M}} \mathrm{l}=15,47 \mathrm{dtk} / \mathrm{smp}$

Peluang Antrian (QP\%)

Batas nilai peluang antrian $\mathrm{QP} \%$ ditentukan dari huoungan empiris antara peluan antrian Qp\% dan derajat kejenuhan Ds

Batas nilai bawah

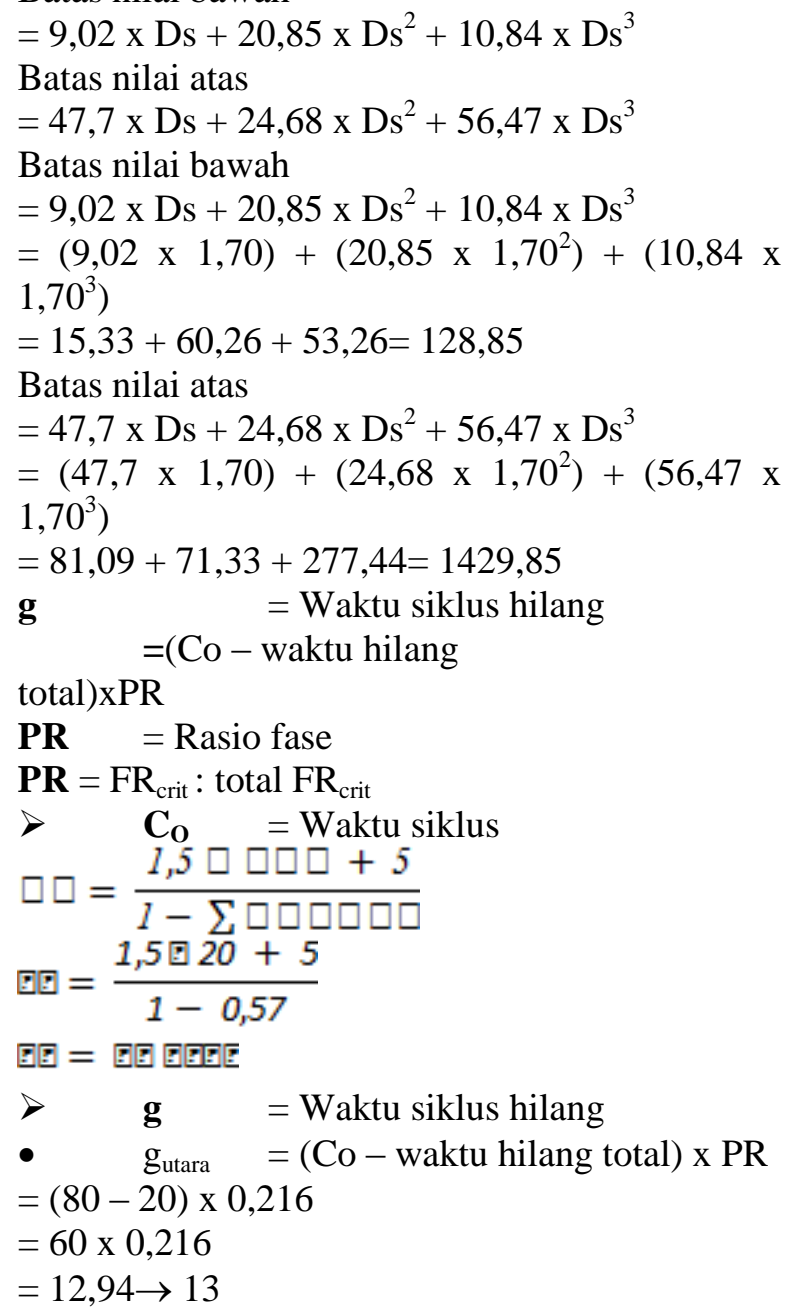

- $\mathrm{g}_{\text {selatan }}=(\mathrm{Co}-$ waktu hilang total $) \times \mathrm{PR}$

$=(80-20) \times 0,227$

$=60 \times 0,227$

$=13,65 \rightarrow 14$

- $\mathrm{g}_{\text {timur }}=(\mathrm{Co}-$ waktu hilang total $) \times \mathrm{PR}$

$=(80-20) \times 0,359$

$=60 \times 0,359$

$=21,57 \rightarrow 21$

- $\mathrm{g}_{\text {barat }}=(\mathrm{Co}-$ waktu hilang total $) \times \mathrm{PR}$

$=(80-20) \times 0,197$

$=60 \times 0,197$

$=11,85 \rightarrow 12$

$$
\begin{aligned}
& \text { Waktu hijau efektif total } \\
& =\mathrm{C}_{\mathrm{o}}-\mathrm{Lti} \\
& =80-20 \\
& =60 \mathrm{detik}
\end{aligned}
$$


Fase I (Selatan)

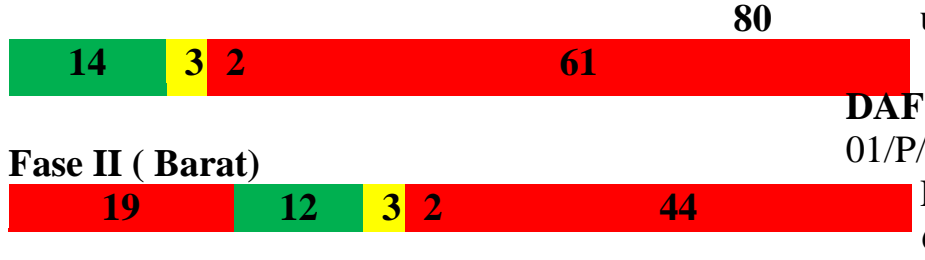

jalan minimal 50 meter dari persimpangan untuk mengurangi hambatan samping.
Fase III (Utara)

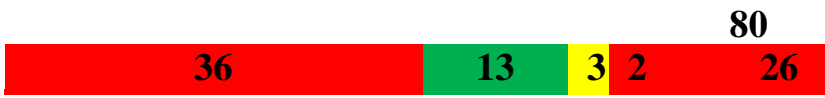

\section{Fase III(Timur)}

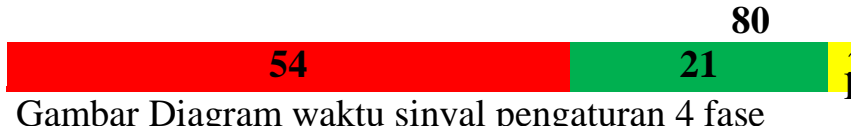

\section{SIMPULAN DAN SARAN \\ Simpulan}

Berdasarkan hasil analisis maka dapat disimpulkan sebagai berikut:

1. Pada kondisi awal simpangTanjung Alam di Kabupaten Agam merupakan persimpangan tak bersinyal dengan konflik antar kendaraan yang bergerak dari arah yang saling berlawanan. Untuk kondisi geometrik simpang arah Jl. Raya Mansoer Thaib (Utara) merupakan jalan dengan lebar terkecil yaitu sebesar 6 meter.

2. Berdasarkan perhitungan persimpangan tidak bersinyal untuk kondisi eksisting diketahui bahwa simpang Tanjung Alam di Kabupaten Agam termasuk persimpangan dengan kode simpang 422 dimana mempunyai 4 lengan simpang, 2 lajur jalandan 2 lajur jalan utama.Kapasitas (C) $3921 \mathrm{smp} / \mathrm{jam}$, Derajat Kejenuhan (DS) 1,7 dan Tundaan (D) $D_{\text {tot }}=14,39 \mathrm{dtk} / \mathrm{smp}$.

3. Dari pengaturan fase sinyal didapat nilai Waktu Siklus $(\mathrm{Co})$ untuk 4 fase $=80$ detik dengan waktu hijau aktual (Selatan $=14$ detik, Barat $=12$ detik, Utara $=13$ detik dan Timur $=21$ detik).

\section{Saran}

1. Perlu diaktifkan kembali Alat Pemberi Isyarat Lalu Lintas (APILL) untuk mengatur fase kendaraan sehingga dapat memperkecil nilai tundaan yang terjadi karena Simpang Tanjung Alam di Kabupaten Agam memiliki potensi kemacetan yang cukup besar.

2. Perlu dilakukan penerapan peraturan pelarangan parkir kendaraan di pinggiran

\section{DAFTAR PUSTAKA}

01/P/BNKT/1991 Direktorat Bina Marga Direktorat Pembinaan Jalan Kota Tata Cara Pemasangan Rambu Dan Marka Jalan Kota. Jakarta, 1991.

Clarkson, O, dan Hicks, G. R, 1999. Teknik Jalan Raya. Erlangga, Jakarta.

Direktorat Jendral Bina Marga Republik Indonesia, Direktorat Bina Jalan Kota Manual. Kapasitas Jalan Indonesia, February 1997.

Hobbbs, F.D. 1995. Perencanaan dan Teknik Lalulintas. Gadjah Mada University Press, Yogyakarta.

Keputusan Mentri 61 Perhubungan Rambu Lalu lintas Di Jalan. Jakarta, 1993.Pedoman Teknis Pengaturan Lalu Lintas di Persimpangan Berdiri Sendiri

Suadi Nugroho, Kelayakan Pemasangan Lampu Lalu Lintas Terkoordinasi di Kota Tegal, Universitas Diponegoro Semarang, Kota Semarang, 2004.

Tamin, Ofyar Z. 2000. Perencanaan dan Pemodelan Transportasi, Edisi ke-2. Teknik Sipil Institut Teknologi Bandung, Bandung.

Tamin, Ofyar Z. 2003. Perencanaan dan Pemodelan Transportasi: Contoh soal dan aplikasi, Teknik Sipil Institut Teknologi Bandung, Bandung.

Warpani, S. 1998. Rekayasa Lalu Lintas. Bharata, Jakarta.

$\begin{array}{lr}\text { Fakultas Teknik UMSB } & \text { ISSN 2599-2081 } \\ \text { EISSN 2599-2090 }\end{array}$

